\title{
Market-based measures for greenhouse gas emissions from ships: a review
}

\author{
Harilaos N. Psaraftis
}

Received: 6 December 2011 / Accepted: 28 March 2012 /Published online: 19 April 2012

(C) World Maritime University 2012

\begin{abstract}
The purpose of this paper is to review several distinct proposals for marketbased measures (MBMs) that are under consideration by the International Maritime Organization (IMO) for greenhouse gases (GHGs). Thus far, some ten distinct MBM proposals have been submitted to the IMO. The paper discusses the general concept of an MBM, the mechanisms used by MBMs, and attempts to discuss the pros and cons of the submitted proposals, according to some specific criteria.
\end{abstract}

Keywords Greenhouse gas emissions $\cdot$ Market-based measures $\cdot$ Emissions trading scheme $\cdot$ International GHG fund $\cdot$ Bunker levy $\cdot$ Energy efficiency design index

\section{Introduction}

Progress on air emissions from ships has been mixed. In 2008, the Marine Environment Protection Committee (MEPC) of the International Maritime Organization (IMO) unanimously adopted amendments to the MARPOL Annex VI regulations that deal with sulphur oxide (SOx) and nitrous oxide (NOx) emissions. SOx and NOx are not greenhouse gases (GHGs) but are pollutants that cause acid rain and other undesirable effects. On the GHG front, carbon dioxide $\left(\mathrm{CO}_{2}\right)$ is the most prevalent of GHGs that are responsible for climate change. However, in spite of much discussion, shipping is still not being included in the United Nations Framework Conference on Climate Change (UNFCCC) global emissions reduction target for $\mathrm{CO}_{2}$ and other GHGs, and in fact, until very recently, shipping was the only mode of transport for which GHG emissions were not regulated. The era of non-regulation for shipping GHGs officially came to an end in July 2011, when, after considerable debate and fierce opposition from a number of developing countries, the MEPC adopted the Energy Efficiency Design Index (EEDI)

\footnotetext{
H. N. Psaraftis $(\square)$

Laboratory for Maritime Transport, National Technical University of Athens, Iroon Polytechneiou 9, Zografou 15773 Athens, Greece

e-mail: hnpsar@gmail.com
} 
for new ships. Even so, further measures to curb future GHG growth in shipping are being sought with a high sense of urgency.

It has been customary to break down the spectrum of measures to reduce GHG emissions into the following major categories:

First, technological measures include more efficient (energy-saving) engines, more efficient ship hulls and designs, more efficient propellers, cleaner fuels (low carbon content, LNG), alternative fuels (fuel cells, biofuels, etc.), devices to trap exhaust emissions (scrubbers, etc.), energy recuperation devices, "cold ironing" in ports, various kites, and others.

Second, logistics-based (or operational) measures include speed optimization, optimized weather routing, optimal fleet management and deployment, efficient supply chain management, and others that impact the logistical operation.

Third, we have what we call market-based measures or MBMs. These include Emissions Trading Schemes (ETS), an International Fund based on a contribution imposed on fuel, and a variety of others, as will be explained later.

We note that the partition into the above three categories is, in some respects, artificial. This is so because an MBM may induce the ship owner to adopt logisticsbased measures (in the short run) and technological measures (in the long run) that would result in GHG emissions reductions.

This paper focuses on the third categories of measures, the MBMs, even though (and for the reasons that we alluded to above) it will also touch upon the other two categories whenever warranted.

To obtain some insights into the possible role of MBMs, consider the practice of slow steaming, widely applied in recent times mainly to reduce fuel costs and help sustain a fragile market by absorbing excess shipping capacity. From basic naval architecture, the dependency of fuel consumption on ship speed is at least cubic. GHG emissions being directly proportional to fuel consumed, a simple way to reduce these emissions, perhaps drastically, is for a ship to slow down.

Slowing down can be done at two levels. The first level is logistics-based (operational), that is, has an existing ship go slower than its design speed. This may involve installing 'slow steaming kits' to allow engines to operate efficiently at reduced power, or even 'derating' a ship's engine so that the slower speed can be attained. The second level is technological (strategic), that is, build future ships with a reduced installed horsepower so that they cannot go more than a prescribed speed.

Designing ships of significantly lower operating speeds seems to be a projected trend that may be the norm for the future, especially for containerships. The new 18,000 TEU 'triple E' boxships that Maersk has ordered will have design speeds that are lower than the current (19 knots versus 25.5 for the 'Emma Maersk') and are claimed that they will operate at fuel consumption of $50 \%$ less than the industry average and $20 \%$ better than the existing best.

Even though slow steaming has been practised historically without any MBM being applied, it is clear that an MBM can affect the extent of this practice. At the operational level, paying more for bunker fuel via an imposed charge on fuel may, depending on the state of the market, induce slower steaming. At the strategic level, the same measure may make a ship owner purchase a ship that is more fuel efficient, or just cannot go very fast. Either way, less GHGs would be produced. These emissions reductions are known as 'in sector' reductions. 
By making a ship owner pay for his ship's $\mathrm{CO}_{2}$ emissions, an $\mathrm{MBM}$ is an instrument that implements the 'polluter pays' principle. In that sense, it helps internalise the external costs of these emissions. Also monies raised by an MBM can be used to reduce $\mathrm{CO}_{2}$ emissions outside the marine sector, for instance by purchasing what are known as 'offsets'. Such offsets could, for instance, be used to invest in projects such a wind farm in New Zealand, a solar cell farm in Indonesia, or others, and so contribute to GHG reduction outside the marine sector. These are known as 'out of sector' reductions.

The rest of this paper is organized as follows. Section 2 discusses some basic concepts including that of the marginal abatement cost curve. Section 3 outlines the MBM proposals currently on the table at the IMO. Section 4 comments on the modelling effort to evaluate these proposals. Section 5 reviews the MBM proposals in more detail. Section 6 presents a horizontal comparison of the MBM proposals and finally Section 7 discusses the way ahead and presents the conclusions.

\section{Basic concepts}

Before we proceed with MBMs, some basic concepts are in order.

\subsection{Carbon coefficients}

There is a linear relationship between fuel burned and $\mathrm{CO}_{2}$ produced, with the proportionality constant being known as the 'carbon coefficient'. The IMO GHG study of 2000 used a coefficient of 3.17 (tonnes of $\mathrm{CO}_{2}$ per tonne of fuel) independent of fuel type, but its 2009 update (Buhaug et al. 2009) used slightly lower coefficients, which ranged from 3.021 for heavy fuel oil to 3.082 for marine diesel oil. The factor that IMO uses for EEDI reference line calculations is 3.11 for both main engine and auxiliaries. For alternative fuels such as LNG, the carbon coefficient can range from 2.6 to 2.8. This feature makes LNG more attractive than fossil fuels for propulsion, among other advantages, such as lack of sulphur and other substances and producing more energy per unit weight than fossil fuels.

\subsection{Marginal abatement costs}

Let us call $\mathrm{A}$ a well-defined available measure to avert $\mathrm{CO}_{2}$. For instance, measure A can be a more efficient hull form, a more fuel-efficient engine, a more efficient propeller, a device such as a kite that can save energy, etc. Suppose that we implement measure A on a given ship and we compare the ship without measure A with the ship with measure $\mathrm{A}$, ceteris paribus.

Define also:

$\triangle \mathrm{GCOST}(\mathrm{A}) \quad$ the total gross cost in implementing measure A, defined as the gross difference in annualized costs of the ship with measure $\mathrm{A}$, minus those costs without measure A, gross meaning excluding fuel costs

$\triangle$ FUEL(A) the total annual fuel consumption averted by implementing measure A, for the same ship 
$\triangle \mathrm{NCOST}(\mathrm{A}) \quad$ the total net cost in implementing measure $\mathrm{A}$, defined as the net difference in annualized costs of the ship attributed to measure A, net meaning including fuel costs

$\Delta \mathrm{CO}_{2}(\mathrm{~A}) \quad$ the total tons of $\mathrm{CO}_{2}$ averted by measure $\mathrm{A}$

PFUEL the average price of fuel over a year, and

F

the carbon coefficient (between 3.02 and 3.11)

Then the marginal abatement cost (MAC) of measure A is defined as follows.

$$
\operatorname{MAC}(\mathrm{A})=\Delta \mathrm{NCOST}(\mathrm{A}) / \Delta \mathrm{CO}_{2}(\mathrm{~A})
$$

Given that

$$
\Delta \mathrm{NCOST}(\mathrm{A})=\Delta \mathrm{GCOST}(\mathrm{A})-\Delta \mathrm{FUEL}(\mathrm{A}) \times \mathrm{PFUEL}
$$

and that

$$
\Delta \mathrm{CO}_{2}(\mathrm{~A})=\Delta \mathrm{FUEL}(\mathrm{A}) \times F
$$

it follows that

$$
\operatorname{MAC}(\mathrm{A})=\Delta \mathrm{GCOST}(\mathrm{A}) / \Delta \mathrm{CO}_{2}(\mathrm{~A})-\mathrm{PFUEL} / F
$$

The negative term in the right-hand side of Eq. 1 reflects the savings in costs (per tonne of $\mathrm{CO}_{2}$ averted) due to fuel consumption reduction. This also means that for any measure $\mathrm{A}, \mathrm{MAC}(\mathrm{A})$ can be negative if the price of fuel is high enough. Measures for which $\triangle \mathrm{GCOST}(\mathrm{A})$ is low are also more likely to have a negative MAC(A) than other measures for which these costs are high.

A negative MAC means that the ship owner would have an economic incentive to implement the respective measure. Doing so would increase his profits, and, as an important side effect, would also reduce $\mathrm{CO}_{2}$. It would be a win-win proposition and would not need a regulation mandating the measure. Conversely, if the MAC of a measure is positive, then the ship owner would have no incentive to adopt it. The measure would have to be mandated in order to be implemented.

An important corollary of the above analysis is that even if a 'do-nothing' MBM is adopted, it would lead to some $\mathrm{CO}_{2}$ reduction, as all measures that have a negative MAC would be implemented. With fuel prices projected to rise, more and more such measures would become relevant and cost effective in the future.

\subsection{MAC curves}

If one examines a set of feasible measures to reduce $\mathrm{CO}_{2}$ and compute the MACs for such measures applied to the world fleet, one comes up with what is known as the MAC curves. Several attempts to construct MAC curves are known, see for instance Alvik et al. (2009); Eide et al. (2010) and IMAREST (2011). Figure 1 shows such a curve, taken from the Expert Group report on MBMs (IMO 2010b) and carried out by DNV, which was commissioned by the IMO for the task.

It is important to realize that the MAC curves directly depend on the projected price of fuel, as Eq. 1 above stipulates. In that respect, DNV and the MBM Expert 


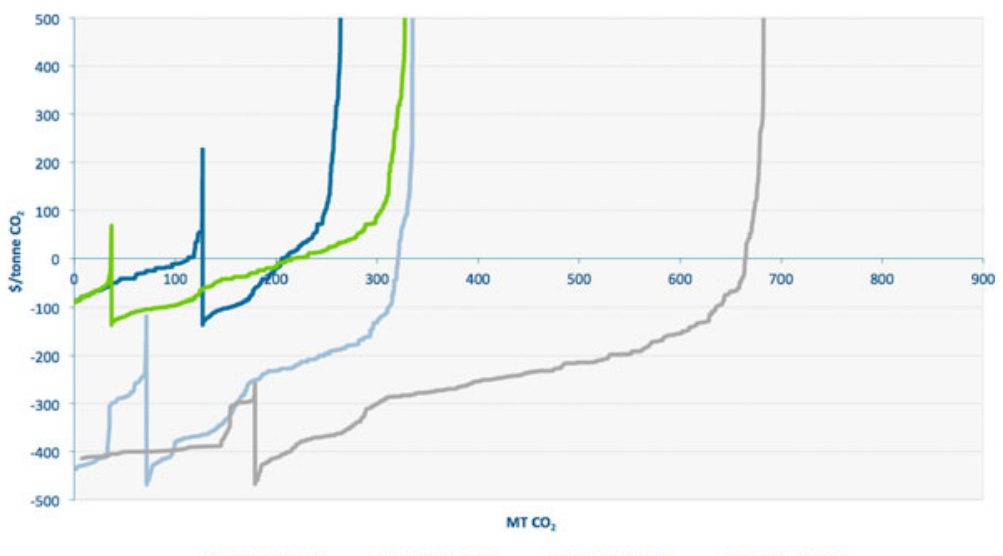

Fig. 1 Sample MAC curves by DNV. Source: IMO (2010b)

Group examined a variety of scenarios on projected future parameters including fuel prices (more on this in Section 4).

\subsection{Effect of a bunker levy on MAC curves}

The MAC curve can be very useful if one wants to evaluate the effect of a bunker levy on $\mathrm{CO}_{2}$ emissions. Figure 2 below shows how. The figure shows two MAC curves. The one on top is before a levy is applied, and the one below is after the levy. Applying a levy equal to LEVY means that the price of fuel will increase to PFUEL + LEVY.

Assuming that LEVY $>0$ and that fuel prices do not change as a result of the levy, the MAC curve will uniformly go down by LEVY/F. This means that we can easily find the $\mathrm{CO}_{2}$ reduction $\Delta \mathrm{CO}_{2}$, if we assume that for every fuel price/levy the equilibrium $\mathrm{CO}_{2}$ emissions will be at the point where $\mathrm{MAC}=0$.

A first-order approximation of $\Delta \mathrm{CO}_{2}$ will be $\mathrm{LEVY} /(F \times s)$, where $s$ is the slope of the MAC curve at MAC $=0$. However, one has to be careful as from Fig. 1 one can see that this slope can vary widely.

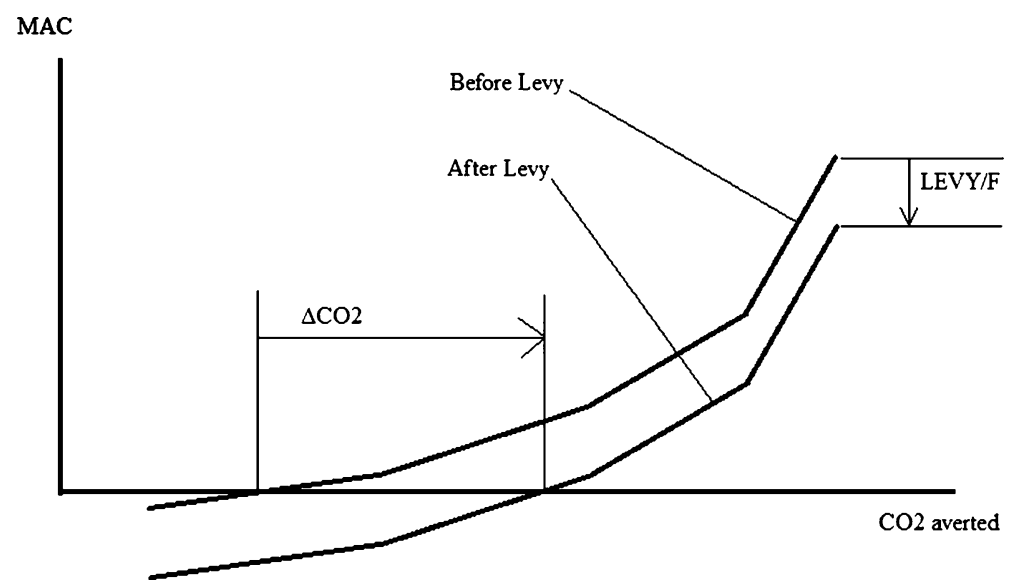

Fig. 2 Using MAC curves to determine the effect of a bunker levy 


\section{The MBM proposals on the table}

Following the update of the IMO GHG study in 2009 (Buhaug et al. 2009), IMO activity on GHGs has been largely on two "parallel" tracks. The first track mainly concerns the so-called Energy Efficiency Design Index (EEDI). EEDI is an index that purports to measure the energy efficiency of a ship, defined as the ratio of emissions from the ship divided by the transport work of the ship. The second track concerns MBMs. It is interesting that discussion on these two tracks has been conducted thus far with no apparent connection between the two, even though both tracks concern the same objective (reduce GHG emissions from ships). It will also be seen later that in reality these tracks are not disjoint, as some of the proposed MBMs embed EEDI in their formulation.

For MBMs, an Expert Group was appointed by the IMO's secretary general after solicitation of member states and was tasked to evaluate as many as ten separate MBM proposals, submitted by various member states and other organizations. All submitted MBM proposals describe programs and procedures that would target GHG reductions through either 'in-sector' emissions reductions from shipping or 'out-ofsector' reductions via the collection of funds to be used for mitigation activities in other sectors that would contribute towards global reduction of GHG emissions.

The IMO formulated nine criteria for evaluation of GHG reduction measures, including MBMs, the following:

1. Environmental effectiveness

2. Cost effectiveness and potential impact on trade and sustainable development

3. The potential to provide incentives to technological change and innovation

4. Practical feasibility of implementing MBM

5. The need for technology transfer to and capacity building within developing countries LDC, in particular the (least developed countries) and the small island development states (SIDS)

6. The relation with other relevant conventions (UNFCCC, Kyoto Protocol and WTO) and the compatibility with customary international law

7. The potential additional administrative burden and the legal aspects for national administrations to implement and enforce MBM

8. The potential additional workload, economic burden and operational impact for individual ships, the shipping industry and the maritime sector as a whole, of implementing MBM

9. The compatibility with the existing enforcement and control provisions under the IMO legal framework.

Brief descriptions of each of the ten original IMO MBM proposals are as follows (see IMO (2010g) for more details):

1. The International Fund for Greenhouse Gas emissions from ships (GHG Fund) originally proposed by Cyprus, Denmark, the Marshall Islands, Nigeria, and the International Parcel Tanker Association-IPTA (IMO 2010b)

Liberia and the Republic of Korea were later added as co-sponsors of this MBM. This Fund would establish a global reduction target for international shipping, set by either the UNFCCC or the IMO. Emissions above the target line would be offset 
largely by purchasing approved emission reduction credits. The offsetting activities would be financed by what the proposers call a 'contribution' paid by ships on every tonne of bunker fuel purchased. It is envisaged that contributions would be collected through bunker fuel suppliers (option 1) or via direct payment from ship owners (option 2). The contribution rate would be adjusted at regular intervals to ensure that sufficient funds are available to purchase project credits to achieve the agreed target line. Any additional funds remaining would be available for adaptation and mitigation activities via the UNFCCC and R\&D and technical co-operation within the IMO framework.

2. The Leveraged Incentive Scheme (LIS) to improve the energy efficiency of ships based on the International GHG Fund proposed by Japan (IMO 2010j)

This resembles the aforementioned Fund scheme with an important difference: The concept of the Leveraged Incentive Scheme is that a part of the GHG Fund contributions, which are collected on marine bunker is refunded to ships meeting or exceeding agreed efficiency benchmarks and labelled as "good performance ships". To that effect, the EEDI index is the main instrument in determining which ships are efficient and should receive the refunds. In that sense, this MBM is a hybrid one, as it includes EEDI as part of its formulation.

3. Achieving reduction in greenhouse gas emissions from ships through Port State arrangements utilizing the ship traffic, energy and environment model, STEEM (PSL) proposal by Jamaica (IMO 2010i)

Under this MBM, member states participate in levying a uniform emissions charge on all vessels calling at their respective ports based on the amount of fuel consumed by the respective vessel on its voyage to that port (not bunker suppliers). The proposal is directly aimed at reducing maritime emissions of $\mathrm{CO}_{2}$ without regard to design, operations or energy source. The Port State Levy would be structured to achieve the global reduction targets for GHG and could be leveraged in a manner as proposed by Japan to reward vessels exceeding efficiency targets.

4. The US proposal to reduce greenhouse gas emissions from international shipping, the Ship Efficiency and Credit Trading (SECT) (IMO 2010m)

This MBM is designed to focus emission reduction activities just in the shipping sector. Under SECT, all ships, including those in the existing fleet, would be subject to mandatory energy efficiency standards, rather than a cap on emissions or a surcharge on fuel. As one means of complying with the standard, SECT would establish an efficiency-credit trading programme. The stringency level of these efficiency standards would be based on energy efficiency technology and methods available to ships in the fleet. These standards would become more stringent over time, as new technology and methods are introduced. Similar to the EEDI, these efficiency standards would be based on a reduction from an established baseline and would establish efficiency standards for both new and existing ships. As the LIS MBM by Japan, the SECT MBM by the USA is a hybrid MBM, as it embeds EEDI within its formulation. However, the mechanism is different. Under SECT, ships would trade on EEDI. A 'good EEDI' ship would sell credits to a 'bad EEDI' ship. 
5. Vessel Efficiency System (VES) proposal by World Shipping Council (WSC) (IMO 2010n)

VES would establish mandatory efficiency standards for both new and existing ships. Each vessel would be judged against a requirement to improve its efficiency by $X \%$ below the average efficiency (the baseline) for the specific vessel class and size. Standards would be tiered over time with increasing stringency. Both new build and existing ships would be covered. New builds must meet the specified standards or they may not operate. Existing ships may comply by improving their efficiency scores through technical modifications that have been inspected and certified by the administration or recognized organizations. Existing ships failing to meet the required standard through technical modifications would be subject to a fee applied to each tonne of fuel consumed. The total fee applied (non-compliant ships only) would vary depending upon how far the vessel's efficiency (as measured by the EEDI) falls short of the applicable standard. This is another example of a hybrid MBM, as it embeds EEDI within its formulation.

6. The Global Emission Trading System for international shipping proposal by Norway (IMO 2010k)

This MBM would set a sector-wide cap on net emissions from international shipping and establish a trading mechanism to facilitate the necessary emission reductions, be they in-sector or out-of-sector. The use of out-of-sector credits allows for further growth of the shipping sector beyond the cap. In addition, the auction revenue would be used to provide for adaptation and mitigation (additional emission reductions) through UNFCCC processes and R\&D of clean technologies within the maritime sector. A number of allowances (ship emission units) corresponding to the cap would be released into the market each year. It is proposed that the units would be released via a global auctioning process. Ships would be required to surrender one ship emission unit or one recognized out-of-sector allowance or one recognized outof-sector project credit, for each tonne of $\mathrm{CO}_{2}$ they emit. The Norwegian ETS would apply to all $\mathrm{CO}_{2}$ emissions from the use of fossil fuels by ships engaged in international trade above a certain size threshold. The proposal also indicates that limited exemptions could be provided for specific voyages to Small Island Developing States.

7. Global Emissions Trading System for international shipping proposal by the UK (IMO 20101)

This is very similar in most respects to the global ETS proposal by Norway. Two aspects of the UK proposal that differ from the Norwegian ETS proposal are the method of allocating emissions allowances and the approach for setting the emissions cap.

8. Further elements for the development of an Emissions Trading System for International Shipping proposal by France (IMO 2010c)

This MBM sets out additional detail on auction design under a shipping ETS. In all other aspect, the proposal is similar to the Norwegian proposal for an international ETS. 
9. Market-based instruments: a penalty on trade and development proposal by the Bahamas (IMO 2010a)

This MBM does not set explicit standards or reductions to be achieved in the shipping sector or out-of-sector for GHG reductions. The proposal clearly sets forth that the imposition of any costs should be proportionate to the contribution by international shipping to global $\mathrm{CO}_{2}$ emissions. The Bahamas has indicated that it is assuming that mandatory technical and operational measures would be implemented such as the EEDI.

10. A rebate mechanism for a market-based instrument for international shipping proposal by IUCN (IMO 2010h)

This MBM focuses on a rebate mechanism to compensate developing countries for the financial impact of an MBM. This rebate mechanism would 'piggy back' any of the other MBMs. A developing country's rebate would be calculated on the basis of their share of global costs of the MBM, using readily available data on a developing country's share of global imports by value as a proxy for that share (or another metric such as value distance if data become available).

In addition to the above, the following developments took place after the above 10 MBMs were submitted:

1. A German ETS proposal (IMO 2010d) that was not included in the original MBM list for administrative reasons was reinstated as part of the MBM roster.

2. The LIS and VES proposals were combined into what was relabeled the Efficiency Incentive Scheme (EIS) (IMO 2011b)

3. The Bahamas submitted what they called an evolution of their original proposal (IMO 2011a), of which more later.

\section{Modelling to evaluate the MBM proposals}

After considerable discussion, a 300+ page report (IMO 2010b) evaluating the MBM proposals was prepared by the MBM Expert Group and was presented and discussed at MEPC 61 (September 2010). The report went at length in assessing each MBM according to the evaluation criteria in modelling future scenarios and in assessing the impact of MBMs on trade and developing countries. However, the report contained no horizontal comparison of MBMs and no recommendation as to which MBMs should be further pursued.

The Expert Group's modelling effort, which also involved the work of external consultants, was to develop and apply a model to make quantitative estimates of emission reductions, revenues generated, costs and other attributes of each MBM proposal. Modelling scenarios included:

- Two growth rates $(1.65 \%$ and $2.8 \%)$

- Three targets lines/caps for GHG Fund and ETS (0 \%, $10 \%$ and $20 \%$ below 2007 level)

- $28 \%$ revenue used for mitigation for rebate mechanism and $25 \%, 50 \%$ and $75 \%$ revenue refunded for LIS

- Low, medium and high stringency standards for VES and SECT 
- Two carbon price scenarios (medium and high) and two fuel price scenarios (reference and high).

Details can be found in IMO (2010g).

Even though this effort is certainly worthy of note, reservations are expressed herewith for some of the modelling assumptions. As an example (which is one of several), a key assumption was made that an increase in fuel prices of $100 \%$ over the long-term will result in a $4 \%$ reduction in emissions below the so-called "Business As Usual" scenario. However, this percentage ( $4 \%$ or other) critically depends on the slope of the marginal abatement cost (MAC) curve at the point it crosses the $x$-axis (see Figs. 1 and 2). Therefore, the fixed $4 \%$ assumption is not necessarily correct. As illustrated by the DNV MAC curves for the 72 scenarios examined (see Fig. 1) that slope can vary widely from very low to very high (projected future fuel price being the main determinant). In that sense, we have strong reservations on all the numerical results of this model, which are sometimes difficult to follow and, at a minimum, should be interpreted with caution.

The same applies to the numerical results that pertain to a variety of estimates for each MBM proposal, such as in-sector and out-of-sector emissions reductions, revenues generated, costs and a variety of others. Even estimates of $\mathrm{CO}_{2}$ reductions with or without EEDI enacted were produced. All of these results critically depend on a variety of assumptions, which cannot be fully substantiated.

It should also be pointed out that the data and models on the MAC curves supplied to the IMO MBM Expert Group are not fully available to scrutiny, and this significantly limits their usefulness. Both the data and the models are subject to confidentiality clauses. The problem here is, if the models are not made available for scrutiny by the experts or anybody else (remaining virtually a black box) then obviously the correctness of their results cannot be confirmed.

Another reservation that we have concerns the apparent conclusion of the report that the GHG Fund proposal is a weak driver for uptake of in-sector technological measures to reduce emissions, whereas the various ETS proposals are strong drivers. This is not so. In fact, the GHG Fund will result in a much larger reduction in $\mathrm{CO}_{2}$ emissions than an ETS with the same average permit price.

To achieve the same amount of $\mathrm{CO}_{2}$ reduction, if we assume equal efficiency for both systems (which is not necessarily the case), the GHG Fund 'contribution' and the ETS carbon price must be the same. Policy makers get to choose either the target reduction (for the ETS proposal) or the target contribution (for the Fund proposal). Either can be high or low. The target reduction and the target contribution being the policy maker's choice should aim at the same result, i.e. either the same target contribution or the same target reduction. If one goes for a modest target reduction, the carbon price will be low, in fact close to zero according to the MAC curves submitted by DNV. However, a contribution can be fixed for a longer period (a year or more). Permit prices by their nature are both volatile and unpredictable. Owners who are unsure of the carbon price will be facing great difficulty justifying expensive investments in carbon reduction technology.

The same applies as regards revenues generated, which are (again erroneously) postulated in the report to be higher for ETS than for the Fund. If carbon price and $\mathrm{CO}_{2}$ reductions are the same in both schemes, revenues will also be about the same after accounting for efficiency. But as will be argued later, ETS will be more expensive to maintain, and (in that sense) less efficient. This means that in-sector 
$\mathrm{CO}_{2}$ reductions for the GHG Fund proposal can be much higher than those shown in the IMO report.

\section{Review of the MBM proposals}

In the absence of credible modelling results that would lend themselves to a possible horizontal comparison among the MBM proposals, any further discussion of these proposals by necessity will be qualitative and (to some extent) subjective. The rest of the paper makes an attempt at such a discussion.

We structure the discussion as follows: we start by commenting on the Bahamas proposal, the first version of which was essentially a 'do nothing' proposal. Then we comment on MBM proposals that are hybrid, such as those of the USA, Japan and WSC. We follow with the proposals of Jamaica and IUCN. Last but not least, we focus on the GHG Fund and ETS proposals. We close by presenting a summary comparison table of all MBMs according to the IMO criteria, and some other criteria. We are aware of no other similar comparison of these MBM proposals in the literature.

\subsection{The Bahamas proposal}

The Bahamas original proposal (IMO 2010a) was a non-proposal, that is, advocated adopting no MBM, arguing that this would be an obstacle to trade. According to what was presented in Section 2, a 'do-nothing' proposal does not imply zero $\mathrm{CO}_{2}$ reductions, as the measures that have a negative MAC would be implemented and those measures would entail a $\mathrm{CO}_{2}$ reduction. As stated before, fuel price is a key driver to such an outcome.

The Bahamas subsequently submitted an updated MBM proposal (IMO 2011a), which was labelled an evolution of their former proposal. In their updated submission, the Bahamas argued that only through operational and technical measures $\mathrm{CO}_{2}$ emissions can be cut.

The new proposal, among other things, envisions collecting $\mathrm{CO}_{2}$ statistics through either the collection of Energy Efficiency Operational Indicator (EEOI) ${ }^{1}$ data or simply by recording emissions from the funnel using a suitable sensor. The ship would be required to submit emission records to the flag State or recognized organization for annual verification. The statistics collected would then show how much emissions were actually emitted over the data collection period. The problem here is, it is actually impossible to establish a reliable EEOI for any ship with just 23 years of data, especially in the tramp/bulk sector. Also, it is impossible to establish EEOI baselines. In addition, sister ships can have vastly different EEOIs.

\subsection{Hybrid MBM proposals}

There have been three (now two) MBM proposals that are hybrid in the sense that they all include a ship's Energy Efficiency Design Index (EEDI) as part of their formulation. These are the US SECT proposal (IMO 2010m); Japan's LIS proposal

\footnotetext{
${ }^{1}$ EEOI is another energy efficiency index discussed at the IMO, to be used on a voluntary basis. It is based on operational as opposed to design considerations, but resembles EEDI in many respects.
} 
(IMO 2010j), and WSC's VES proposal (IMO 2010n). The last two proposals have been subsequently merged under the name of EIS (IMO 2011b).

All of the above MBM proposals use (each in a different way) the idea of rewarding ships that are supposed to be good environmentally, and in all three EEDI is proposed as a way to measure good environmental performance. A problem may occur if a ship with a low EEDI is not the ship with the lowest $\mathrm{CO}_{2}$. It may emit more $\mathrm{CO}_{2}$ than another ship whose EEDI is higher. A low EEDI may mean an underpowered ship, which, in its attempt to maintain speed in bad weather, may emit more than a ship with a larger engine (IMO 2010e). Another issue is that even though EEDI is supposed to be an index that is intended to be used to assess how future ships can reduce emissions by having good hull forms, efficient engines propellers, etc., if any of these hybrid proposals is adopted, will make it applicable to existing ships as well via the MBM mechanism. Note that thus far there has been no discussion on applying EEDI to existing ships (directly or indirectly), nor is there a plan to have such a discussion. Applying EEDI on existing ships would likely necessitate sea trials and would not be straightforward.

Thus, one would think that keeping these hybrid proposals on the table would necessitate reopening the discussion on EEDI and specifically how EEDI can be applied to existing ships. There is currently no provision for such a discussion at the IMO, neither in the context of the discussion on EEDI, nor in the context of the discussion on MBMs. In fact, the recent adoption of EEDI by the IMO rules out the application of EEDI to existing ships.

\subsection{Jamaica's proposal}

Although in principle Jamaica's approach (IMO 2010i) has merit in that it aims to internalize the external costs of $\mathrm{CO}_{2}$ emissions, important questions regarding its practical implementation can be raised. Monitoring actual emissions is very difficult, even though it is certainly feasible technologically. The idea of measuring emissions produced for each segment of a ship's journey, plus those in port, for all of the world fleet, is a laudable one, but in our opinion we are far away from being able to implement it in a cost-effective manner taking into consideration all the pertinent parameters. Another significant problem is that member states that choose not to participate in this system, or member states that lack proper monitoring and enforcement mechanisms, run the risk of evolving into "mega hubs" of shipping traffic, for the sole purpose of catering to the needs of those who want to evade the scheme.

\subsection{The IUCN proposal}

The main focus of the IUCN proposal (IMO 2010h) is a rebate mechanism which its authors claim is compatible with the Common But Differentiated Responsibilies (CBDR) principle, ${ }^{2}$ while in principle it can be applied to any type of MBM. In that sense, it is a proposal that can 'piggy back' on any other MBM proposal. The

\footnotetext{
${ }^{2}$ The principle of CBDR has been a widely accepted principle that underlines such international agreements as the Kyoto Protocol. The essence of the CBDR has two aspects. The first is common responsibility, which is raised from the concept of common heritage and common concern of humankind and reflects the duty of countries to equally share the burden of environmental protection for common resources; the second is differentiated responsibility, which addresses different social and economic situations across countries.
} 
examples given, however, have some common elements with the GHG Fund proposal, with upper and lower bounds on prices. The rebate mechanism uses a country's share of global imports as a key without specifying which imports.

In principle, such a system might work provided the implementation of the rebate is carried out in a fair way. If the GHG Fund is used as the MBM, a potential problem concerns the fluctuations of the carbon price, even though these are constrained by the upper and lower bounds on price. In that respect, the GHG Fund scheme provides higher investor certainty (unless of course upper and lower bounds are very close or coincide). The administrative costs will of course be higher. They will be those of the MBM system chosen, plus those of administering the rebate system.

\subsection{The GHG Fund and ETS proposals}

\subsubsection{General considerations}

We start by noting that the proposers of the International Fund MBM (submitted by Cyprus, Denmark, Liberia, Nigeria, the Marshall Islands, the Republic of Korea and IPTA) do not call their proposal a 'levy' proposal, much less a 'tax' proposal, and they actually call funds collected a 'contribution'. Essentially, however, and to the extent that this contribution is not voluntary and will have to be imposed to ships if this MBM is adopted, this proposal essentially involves a levy on fuel. Still, we shall keep the name given to this MBM by its proposers when referring to it.

We also note that one of the basic functions of the GHG Fund proposal is to use monies collected so as to purchase "offsets" that can be used to reduce "out-of-sector" $\mathrm{CO}_{2}$ emissions. By doing so, the proposers may run the risk of giving the impression that "insector" $\mathrm{CO}_{2}$ reductions are of lesser importance. This is not necessarily the case, however, since if the contribution is high enough, significant in-sector reductions can be achieved.

We have identified a number of documents that review the levy and ETS systems in both a general context and in specific applications. Below is a brief and nonexhaustive discussion.

On the pro-ETS side, we cite the book by Ellerman et al. (2010) describing experience with the EU ETS. This scheme began operation on 1/1/2005 and now covers more than 10,000 installations and approximately half of the EU's $\mathrm{CO}_{2}$ emissions, being the world's largest company-level "cap-and-trade" system for trading in emissions of $\mathrm{CO}_{2}$. All $27 \mathrm{EU}$ Member States participate fully in the scheme as well as Norway, Iceland and Liechtenstein. The system currently covers $\mathrm{CO}_{2}$ emissions from large emitters in the power and heat generation industries and in selected energy-intensive industrial sectors. The authors of the book believe that although some 'glitches' need to be fixed, the EU ETS is basically sound and can become a prototype for a global climate policy regime.

On the pro-levy side, the US Congressional Budget Office document "Policy Options for reducing $\mathrm{CO}_{2}$ emissions" (CBO 2008) compares cap-and-trade with a levy system. The $\mathrm{CBO}$ paper compares the efficiency and $\mathrm{CO}_{2}$ reduction potential of ETS vs. levy and concludes that a levy on emissions would be the most efficient incentive-based option for reducing emissions and could be relatively easy to implement. Further analysis in said document shows that the $\mathrm{CO}_{2}$ reductions would be nearly double with a levy scheme than a cap and trade scheme. In other words, 
according to $\mathrm{CBO}$, a levy can bring the same environmental result (alternatively: can have the same environmental impact) at half the price of ETS or even less.

Two recent Friends of the Earth (FOE) reports adopt a similar stance. FOE (2009) identifies six central problems with carbon trading, namely that it is ineffective at driving emissions reductions, it fails to drive technological innovation, it leads to lock-in of high-carbon infrastructure, it allows for, and relies on, offsetting, it creates a risk of sub-prime carbon and it provides a smokescreen for lack of action on climate finance by the developed world. FOE (2010) outlines why carbon trading is not the solution to climate change and sets out some of the real solutions for cutting greenhouse gas emissions and delivering climate finance. It calls on national governments to urgently dedicate time and resources to develop and implement these and other more viable, equitable and effective solutions to the climate crisis.

McIlveen and Helm (2010) put forward the case that a carbon tax is the most costeffective measure to reduce $\mathrm{CO}_{2}$ emissions. Exploring the relative theoretical and practical merits of carbon permit trading and carbon taxation, the report makes a strong argument for taxation, given the likely shape of the damage and cost functions associated with climate change - and the possibility that, in choosing a quantitybased approach we might easily pick the wrong quantity. A tax may enable a more long-term, credible carbon price to be established.

\subsubsection{Certainty in cap vs. certainty in price}

One of the main selling points of the various ETS proposals at the IMO is what is claimed as "full certainty on the emission reductions achieved by the mechanism", that is, if one sets a cap on emissions, that cap will absolutely be met. This stems from the fact that $\mathrm{CO}_{2}$ emission allowances (or permits) will be auctioned (at a price that is established by the market) and if no more such allowances exist, a ship would not be able to legally emit $\mathrm{CO}_{2}$. Let us assume for the moment the claim is correct and the cap is enforceable. ${ }^{3}$

A question then is, what should be the cap? For somebody to select it, he or she will have to know what the costs and benefits will be for that particular selection so that this selection is better than another selection. In a sense, the correct level of reduction is the level at which the costs of further reduction are larger than the benefits of that additional reduction. Unfortunately, no one knows what that level is. So, absolute precision in meeting a cap, if it is unclear what the cap should be, is a problem and in our opinion makes that feature less credible. And if a cap is set wrong, it is difficult to change.

On the other hand, even though we may reach the cap we selected, the carbon price that will be established will be completely unknown, being a function of future supply and demand for carbon. All carbon forecasting reports are full of many assumptions and caveats, and still nobody has seen a previous forecast prove accurate. In a University of Cambridge study for the IMO (IMO 2010f), the ETS price starts at US\$ 177 per tonne and then skyrockets to US\$ 3,200 per tonne. It can go the

\footnotetext{
${ }^{3}$ This may be a big assumption. It is suspected that the costs of enforcement will be the high side. Also, as the cap is being reached, carbon price may skyrocket, even years before the cap is reached. Market fears and expectations may skyrocket prices, which may in turn collapse as was the case with the EU ETS.
} 
other way too. EU ETS carbon prices have dropped precipitously as a result of the recent economic crisis and (perhaps) as a result of too many allowances being issued.

Even though in general we may not know exactly what the impact of a levy on $\mathrm{CO}_{2}$ may be, under certain scenarios one can make some pretty good estimates. Devanney (2010) estimates that with a base bunker fuel oil price of US\$ 465/tonne, a US\$ 50/tonne bunker levy will achieve a $6 \%$ reduction in total VLCC emissions over their life cycle. A reasonable estimate of the reduction for a US\$150/tonne levy is $11.5 \%$.

In short, the levy and ETS systems mirror each other. The levy system targets the price and the ETS system targets the quantity of emissions. With ETS we gain cap certainty (with all the previous caveats) and lose price certainty. With a levy scheme, we gain price certainty and can always alter the price to achieve the cap, at least approximately.

From an investor's perspective, facing a predictable price and basing one's investment in green technologies on that price is far less risky than facing an unpredictable price. Investors typically respond to price, not a cap on emissions.

Coming back to shipping, it is also important to note that whereas the effect of a levy on slow steaming is automatic (the owner or whoever pays for the fuel responds to the increased price he faces), with an ETS things are more complicated, for it is nearly impossible to connect a carbon price paid at a certain time to purchase emissions allowances to slow steaming decisions at a later point in time.

\subsubsection{Administrative burden}

Regarding the GHG Fund MBM, a question is which, among the two options proposed is better from an administrative viewpoint. Option 1 collects the money at the bunker supplier level and option 2 collects it at the ship level. At first glance it would seem that option 1 has a lower administrative effort, as involving a lower number of transactions than option 2. In fact, one might consider yet another option, option 3, to collect the money at the refinery level. Theoretically, the higher one goes up the fuel chain, the easier it would be to administer it due to the reduced number of transactions. However, it is not yet clear how each of these options could work in practice, not only from an administrative burden viewpoint, but also in terms of enforcement and evasion avoidance. Some actually believe that none of the above options is viable and instead propose the money to be collected via option 4, by direct measurement of $\mathrm{CO}_{2}$ emissions, via a suitable ultrasound device within a ship's stack (Devanney 2011). However, ship owner circles have raised questions on the reliability of such systems.

The administrative costs for ETS include all those administrative costs associated with option 2 of the GHG Fund proposal (the one which is ship based), plus, many more additional costs associated with issuing the allowances, trading, monitoring compliance, avoiding fraud and others. Therefore, among these two systems, ETS is definitely heavier administrative-wise.

To see the degree of administrative complexity of ETS, one can examine the bareboat or term charterer issue. While a ship is on bareboat or term charter, the charterer is the effective owner. He decides where the ship goes and at what speed. Legally, he is the disponent owner. This is recognized in the charter party which puts 
fuel expense to the charterer's account. If an ETS is going to impact the charterers' decision on what speed the ship will go, it has to do the same. This means a shipping ETS not only has to do all of the above, but it also has to keep track of whether or not the ship was on charter and, if so, who the charterer was when the fuel was purchased. Also, a chartered ship can be sub-chartered and so on.

If alternatively the ETS ignores the ship's charter status and requires permits from the owner for all the fuel consumed on his ship regardless of what the charterer does, looking to the owner to recover the permit cost from the charterer, this would put the owner in an untenable position. He would be responsible for emissions from bunkers which are not his, and permit expenses over which he has no control, and which in many cases are not known until well after the charter is complete. In this way, the uncertain price of the permits would not influence the charterer to reduce speed in order to reduce fuel consumption. All of this is a non-issue for the GHG Fund scheme. Whoever pays for the fuel also pays the Fund's 'contribution'. Incidentally, the GHG Fund MBM (or, in general, a Levy MBM) is the only MBM that can handle slow steaming automatically, by directly impacting the speed decision of either the ship owner (in case of a spot charter) or the charterer (in case of time or bareboat charter).

\subsubsection{Carbon leakage, evasion and fraud}

For ETS, a way to keep the administrative burden from skyrocketing to a high level would be to place limits on coverage, e.g. limit the scheme to ships above a certain size. In fact, this is precisely the reason these limits are suggested in the ETS proposal. If all ships are included the scheme would be unmanageable. Note that according to the IMO 2009 GHG study, if the limit is set at 10,000 GRT, it would amount to 16,000 ships covering some $67 \%$ of total $\mathrm{CO}_{2}$ emissions. Thus, side effects of any limit would be that a percentage of the fleet would be exempted and hence produce $\mathrm{CO}_{2}$. One may see additional side effects like many ships of 9,900 GRT being built if the limit is 10,000 GRT.

Avoidance of carbon leakage is likely to be problematic in ETS. One reason is the high number of exemptions built into the scheme. Already mentioned is the problem associated with the ship size cut-off. See also the exemption of cargoes associated with SIDS. This could result in traffic being diverted to these countries which could develop into mega transhipment hubs, just for the purpose of emissions exemptions.

Thus, under ETS the potential for evasion is substantial. Also, already several fraud cases have been reported within the EU ETS and elsewhere.

\subsubsection{Experience from other ETS contexts}

Even though similarity of ETS with other trading systems is claimed, these other systems concern really different industries, mostly land based, which do not operate on an international basis. There is nothing directly comparable to international shipping.

An ETS system that does operate on an international basis is the EU ETS. However, the structure, economics, legal regime and role of the industries covered by the EU ETS are very different from the equivalent attributes of international 
shipping. A coke oven, a steel plant or a paper mill cannot change flag and relocate if they do not like the stipulations of the ETS (or for any commercial reason, for that matter). The concept of cross-trading, very much prevalent in international shipping, is nowhere to be seen in the sectors covered by the EU ETS, including international aviation, which was included in the EU ETS as of 1 January 2012. That alone might render any allocation scheme unfair and subject to misuse. It is fair to say that the differences among the two sets of sectors are much more than any of the conceivable similarities.

The inclusion of air transport within the EU ETS is an experiment that, at least for the time being, does not seem to proceed very smoothly. For instance, Chinese carriers have been ordered by their government not to contribute to the scheme, and there is widespread opposition from non-EU countries, including the USA, Russia and others. At this point in time, it is too early to tell how the matter will proceed. A fortiori, it is premature to consider aviation as a successful ETS paradigm, some elements of which can be applied to international shipping.

\section{Horizontal assessment of all MBM proposals}

This section is an attempt to assess all MBM proposals in a horizontal manner. What is presented here is qualitative rather than quantitative and obviously represents only the author's own set of conjectures on the subject. As mentioned earlier, no credible quantitative assessment of these proposals is currently available. To our knowledge, there has been no other attempt to make such a horizontal assessment of these proposals.

In that context, Tables 1 and 2 represent how each of the proposals stands with respect to the main criteria and some other criteria. Comments on criteria 6 (compatibility to UNFCCC and other international laws) and 9 (compatibility with existing IMO framework) have been omitted as they are covered by the Expert Group report (IMO 2010g). All ETS proposals are combined.

\section{Way ahead and conclusions}

This paper has described the concept of market-based measures (MBMs) to combat GHG emissions from ships. The MBMs submitted to the IMO have been reviewed. The paper has also presented the author's opinion on these issues, including a comparative evaluation of MBMs on the table.

In March of 2011, an intersessional meeting of the working group on GHG emissions from ships took place, with a view to making progress toward the ultimate selection of an MBM. If the Expert Group report (IMO 2010g) had contained no recommendation on which $\mathrm{MBM}$ should be chosen, the intersessional meeting did not arrive at a similar recommendation either. The same was the case at MEPC 62 (July 2011), as discussion there was entirely devoted to EEDI. In that sense, all MBM proposals submitted to the IMO are still on the table.

Here, it should be mentioned that the European Commission has clearly stated its intent to propose measures tackling GHG emissions from ships at the EU level, in the 


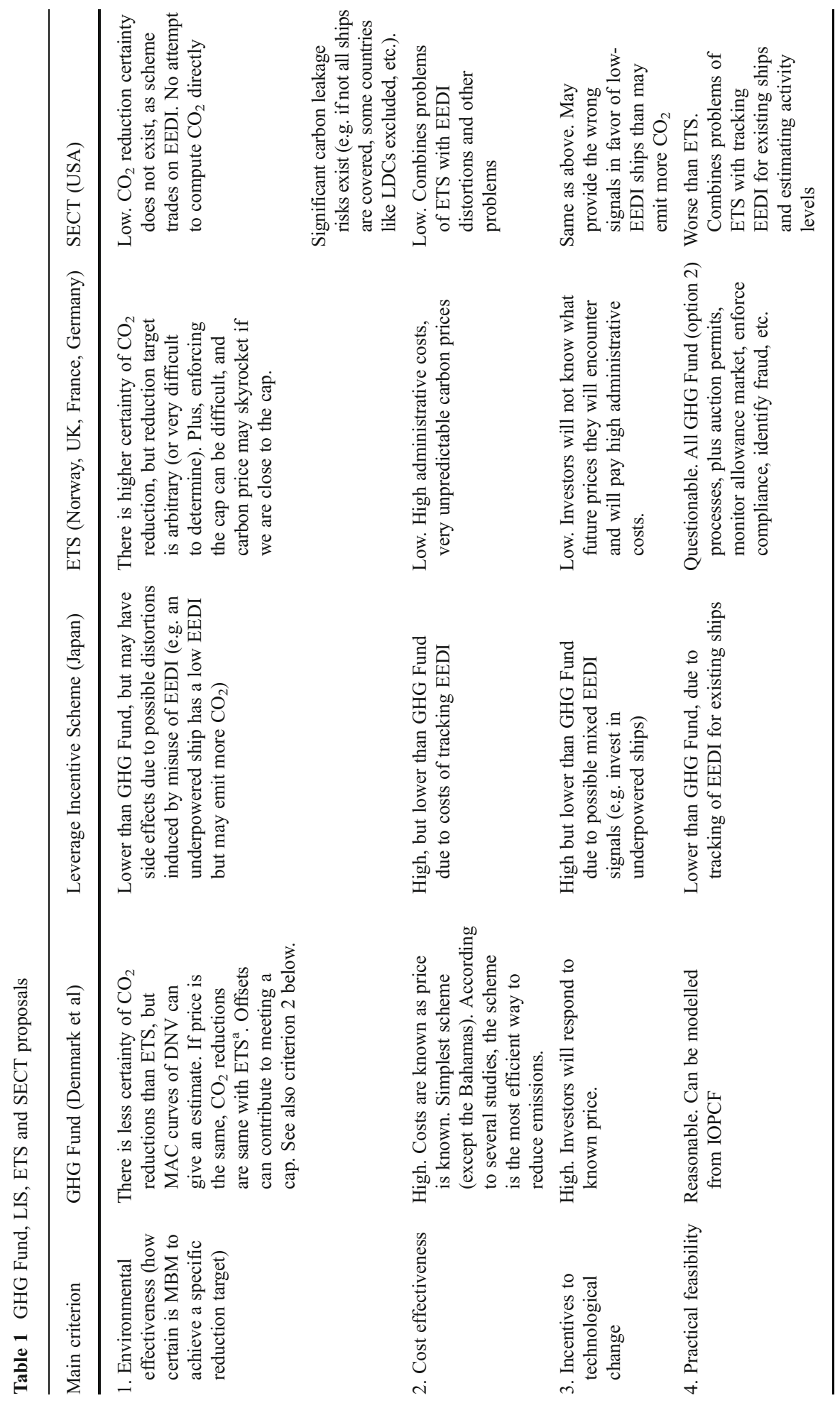




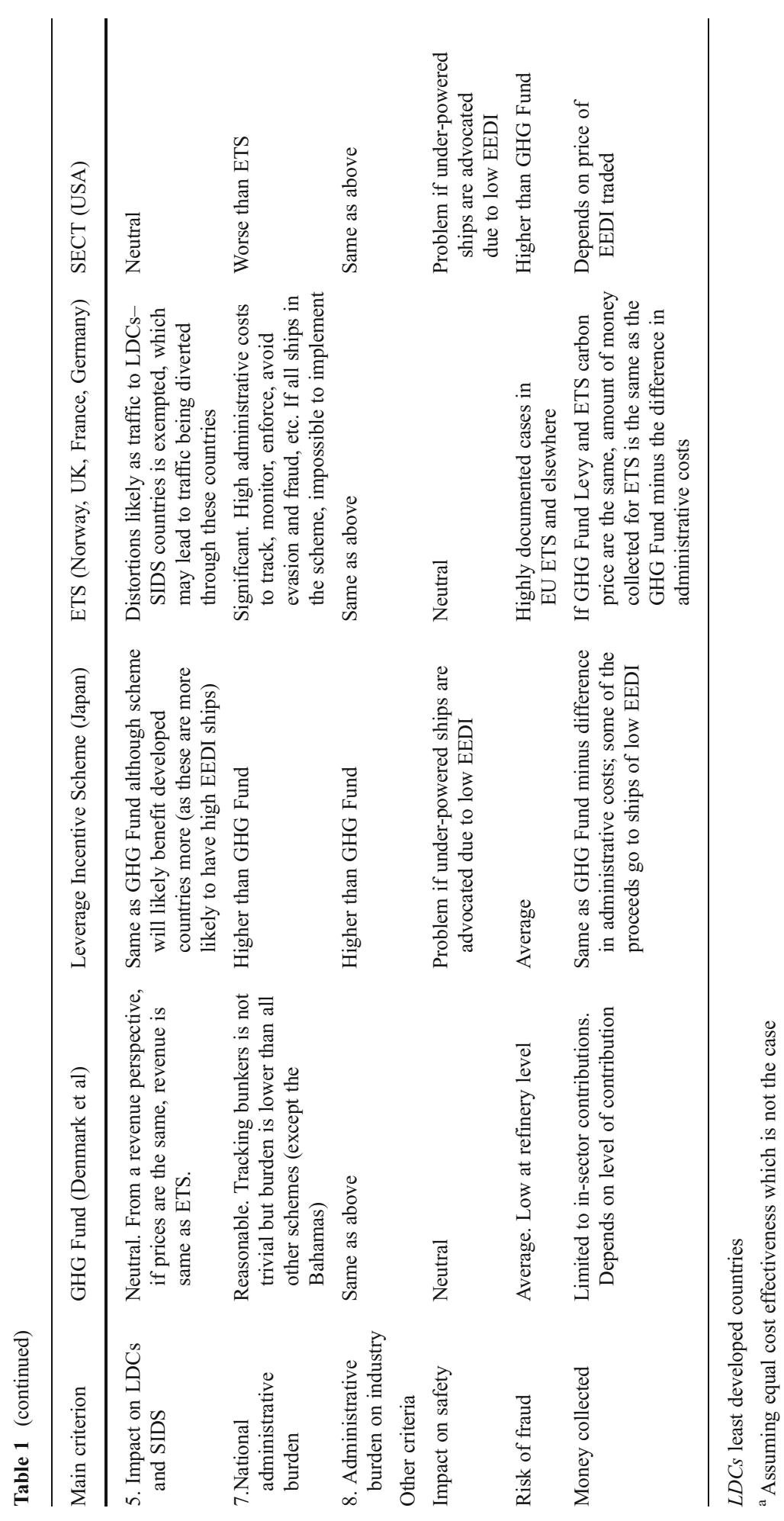




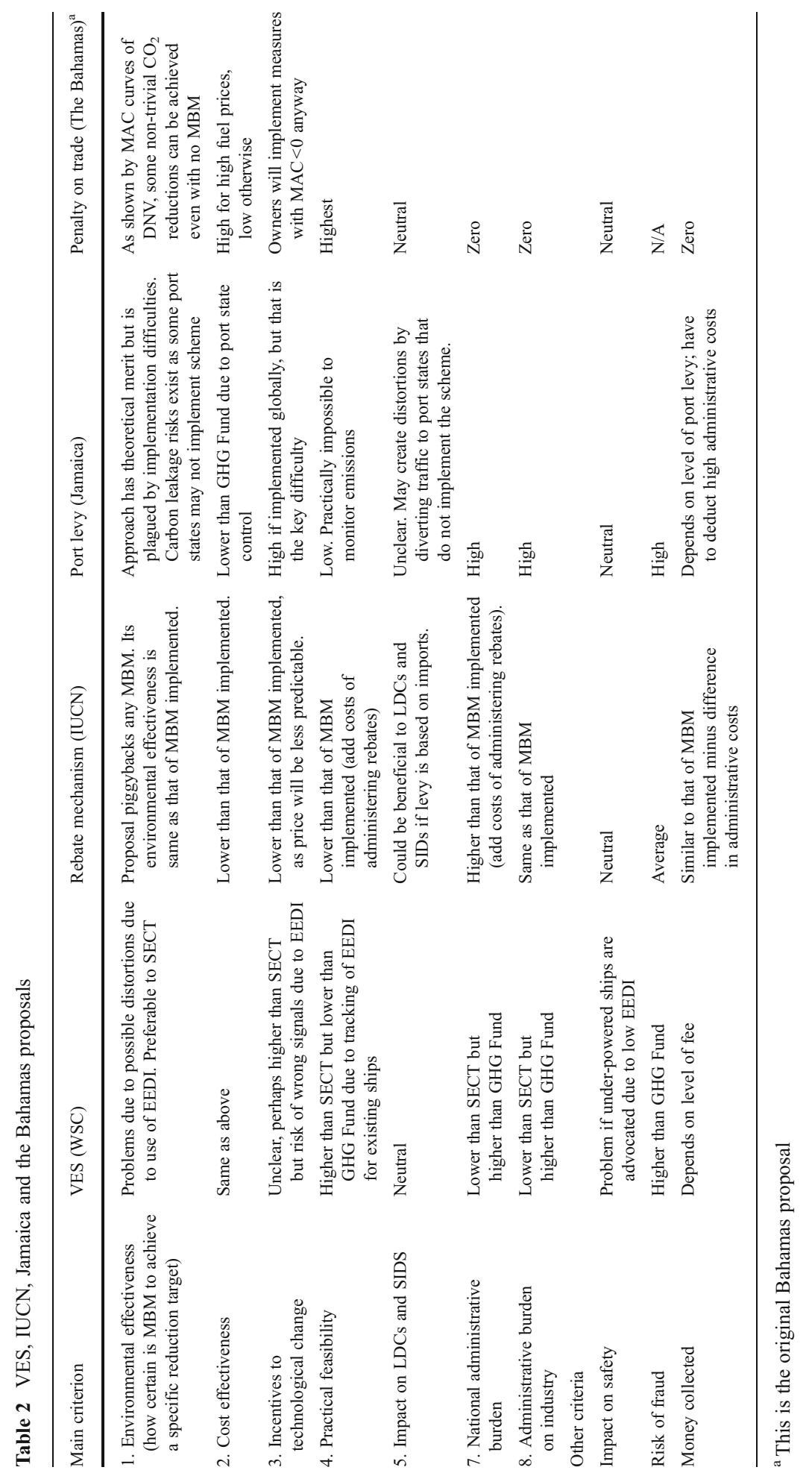


absence of sufficient progress in the framework of IMO by the end of 2011. Given that the condition imposed by the commission calls for ratification of any IMO decision by the EU 27 by December 31, 2011, it is almost a foregone conclusion that the Commission will act on this matter. To that effect, the Commission has stated that adoption of EEDI is not enough. It is not yet clear what the Commission will do, but they have already commissioned a number of studies to advise them on the matter. Speculation in some circles has it that the Commission will probably propose to shipping the ETS that it has instituted for other industries, including the airline industry. But officially the Commission has not stated anything to confirm that and seems to want to keep its options open.

Stakeholder reception of these MBMs has been mixed. The group of developing countries, such as China, India, Brazil and others, are as much against MBMs as they have been against EEDI, mainly on the ground that MBMs are not compatible with the principle of CBDR. Among others, an issue of importance but also disagreement is how monies collected by the MBM would be used for the benefit of developing countries (capacity building, technology transfer, etc.). Among industrial stakeholders, the International Chamber of Shipping, BIMCO and several ship owners associations have come out against an ETS, on the ground that it would be unworkable for the shipping industry. Interestingly enough, these include the German and Norwegian ship owners associations, even though their national maritime administrations are for ETS.

As this paper was being finalized (spring 2012), the IMO process was slated to move on to the next phase, which was to commission an impact assessment study of the MBMs on the table. However at MEPC 63, political considerations and lack of agreement between developed and developing countries prevented a decision on the matter, at least for the time being. One would hope that this difficult process would eventually find a way to move forward. Still, as things stand at this time, the path toward the ultimate selection of an MBM for international shipping seems to be tortuous and long.

Acknowledgments The author was a member of the IMO Expert Group on GHGs. Opinions in this paper are the author's alone. He would like to thank Jack Devanney, George Gratsos, Christos Kontovas and Panos Zachariadis for their assistance in connection to this paper and for some enlightening discussion and debate on MBM and GHG-related topics. The assistance of the Editor-in-Chief and the comments of two anonymous reviewers on a previous version of the paper are also appreciated.

\section{References}

Alvik S, Eide MS, Endresen Ø, Hoffmann P, Longva T (2009) Pathways to low carbon shipping: Abatement potential towards 2030. DNV, Norway

Buhaug Ø, Corbett JJ, Endresen Ø, Eyring V, Faber J, Hanayama S, Lee DS, Lee D, Lindstad H, Markowska AZ, Mjelde A, Nelissen D, Nilsen J, Pålsson C, Winebrake JJ, Wu WQ, Yoshida K (2009) Second IMO GHG study 2009. IMO document MEPC59/INF.10

$\mathrm{CBO}$ (2008) Policy options for reducing $\mathrm{CO}_{2}$ emissions. The Congress of the United States, Congressional Budget Office, Washington DC

Devanney JW (2010) The impact of EEDI on VLCC design and $\mathrm{CO}_{2}$ emissions. www.c4tx.org. Accessed 4 April 2012

Devanney J (2011) Direct taxation is the best way to curb $\mathrm{CO}_{2}$ emissions. http://www.lloydslist.com/11/ sector/ship-operations/article369504.ece. Accessed 4 May 2011

Eide MS, Endresen Ø, Skjong R, Longva T, Alvik S (2010) Cost-effectiveness assessment of $\mathrm{CO}_{2}$ reducing measures in shipping. Marit Policy Manag 36(4):367-384 
Ellerman AD, Convery FJ, de Perthuis C (2010) Pricing carbon: the European union emissions trading scheme. Cambridge University Press, New York

FOE (2009) A dangerous obsession: the evidence against carbon trading and for real solutions to avoid a climate crunch" Friends of the Earth report, 2009. www.foe.co.uk/resource/reports/dangerous_obsession.pdf. Accessed 4 April 2012

FOE (2010) Clearing the air: moving on from carbon trading to real climate solutions. Friends of the Earth report, 2010. www.foe.co.uk/resource/reports/clearing_air_summ.pdf. Accessed 4 April 2012

IMAREST (2011) Marginal abatement costs and cost effectiveness of energy-efficiency measures. IMO doc. MEPC 60/4/10

IMO (2010a) Market-based instruments: a penalty on trade and development proposal by the Bahamas. IMO doc. MEPC 60/4/10

IMO (2010b) The international fund for greenhouse gas emissions from ships (GHG Fund) proposed by Cyprus, Denmark, the Marshall Islands, Nigeria and IPTA. IMO doc. MEPC 60/4/8

IMO (2010c) Further elements for the development of an emissions trading system (ETS) for international shipping proposal by France. IMO doc. MEPC 60/4/41

IMO (2010d) Impact assessment of an emissions trading scheme with a particular view on developing countries. IMO doc. MEPC 60/4/54

IMO (2010e) The Energy Efficiency Design Index (EEDI) and underpowered ships. IMO doc. MEPC 60/4/17

IMO (2010f) Scientific study on international shipping and market-based instruments. IMO doc. MEPC 60/INF.21

IMO $(2010 \mathrm{~g})$ Full report of the work undertaken by the expert group on feasibility study and impact assessment of possible market-based measures. IMO doc. MEPC 61/INF.2

IMO (2010h) A rebate mechanism (RM) for a market-based instrument for international shipping proposal by IUCN. IMO doc. MEPC 60/4/55

IMO (2010i) Achieving reduction in greenhouse gas emissions from ships through Port State arrangements utilizing the ship traffic, energy and environment model, STEEM (PSL) proposal by Jamaica. IMO doc. MEPC 60/4/40

IMO (2010j) The leveraged incentive scheme (LIS) to improve the energy efficiency of ships based on the International GHG Fund proposed by Japan. IMO doc. MEPC 60/4/37

IMO (2010k) The Global Emission Trading System (ETS) for international shipping proposal by Norway. IMO doc. MEPC 61/4/22

IMO (20101) Global Emissions Trading System (ETS) for international shipping proposal by the United Kingdom. IMO doc. MEPC 60/4/26

IMO $(2010 \mathrm{~m})$ The United States proposal to reduce greenhouse gas emissions from international shipping, the Ship Efficiency and Credit Trading (SECT). IMO doc. MEPC 60/4/12

IMO (2010n) Vessel Efficiency System (VES) proposal by world shipping council. IMO doc. MEPC 60/4/39

IMO (2011a) How technical and operational measures are the only direct and effective means to deliver cuts in $\mathrm{CO}_{2}$ emissions. IMO doc. GHG WG $3 / 2$

IMO (2011b) Consolidated proposal of "Efficiency Incentive Scheme" based on the leveraged incentive scheme and the vessel efficiency system. IMO doc. GHG WG 3/3/2

McIlveen R, Helm D (2010) Greener, cheaper. Policy Exchange, London 